\title{
Topical Section: Taiwan, Public Diplomacy, and the World Health Assembly
}

\section{Introduction: Taiwan, Public Diplomacy, and the World Health Assembly}

\author{
Gary D. Rawnsley \\ Dean of the Faculty of Humanities and Social Sciences, \\ University of Nottingham Ningbo China, China \\ gary.rawnsley@eats-taiwan.eu
}

\begin{abstract}
This is an introduction by the guest editor to the topical section on 'Taiwan, Public Diplomacy, and the World Health Assembly' of this issue of the International Journal of Taiwan Studies. The selected four papers, after a double-blind peer review process, were initially presented at a workshop entitled 'Public Diplomacy and Taiwan's Campaign to Join the WHA', organised by the Global Communications Research Centre, Department of International Politics, Aberystwyth University, 28 March 2018.
\end{abstract}

\section{Keywords}

Taiwan - health - public diplomacy - World Health Assembly - World Health Organization - soft power

The first four contributions to this issue of the International Journal of Taiwan Studies are papers that were originally presented at a workshop entitled 'Public Diplomacy and Taiwan's Campaign to Join the WHA', organised by 
the Global Communications Research Centre, Department of International Politics, Aberystwyth University, 28 March 2018. They form a distinct topical section motivated by an ambition to approach Taiwan from a multidisciplinary perspective. Taiwan's exclusion from the World Health Organization (wHo) and World Health Assembly (WHA) requires analyses that are informed by the medical sciences, as well as political science, international relations, and an area studies approach to both Taiwan and China and their interaction. In addition, this topical section, and the workshop on which the essays are based, has chosen to focus on the importance of communications, and specifically public diplomacy, and how they intersect with the political forces shaping Taiwan's interactions on this issue.

Taiwan's public diplomacy capacity is growing, strengthening its management of security threats, the projection of its substantial soft power, and maximising the opportunities arising from Taiwan's considerable contribution to international society. Challenges grow for President Tsai Ing-wen's administration - the unsettling relationship between the United States under President Trump and the People's Republic of China (PRC) which, at the time of writing, has developed into a trade war; the frightening uncertainty about how secure the Korean peninsula really is despite apparent cordial personal relations between Trump and North Korea's Kim Jong-un; allies switching diplomatic recognition from Taiwan to the PRC (Sao Tome and Principe in 2016, Panama in 2017, the Dominican Republic, Burkina Faso, and El Salvador in 2018, the Solomon Islands and Kiribati in 2019), China's intensified 'United Front' strategy against Taiwan, and a more nationalist Chinese government facing its own challenges to stability in Xinjiang and Hong Kong. Kerry Brown's contribution to this topical issue helps us to understand this context and discusses in particular how the Chinese government has restricted Taiwan's space during Tsai Ing-wen's presidency. Brown considers the importance of Taiwan in China's domestic politics in the era of Xi Jinping, especially the rising nationalism in China and the growing sense of historic mission that is informing both policy and propaganda there.

To respond to this environment Taiwan must turn to a range of foreign policy instruments. Public diplomacy, defined as the communicative act of informing, engaging, and influencing publics overseas to advance national and strategic ambitions, may have three principal beneficial effects: encourage the growth of popular familiarity with Taiwan among audiences across the world; generate sympathy for Taiwan's exclusion from mainstream international politics; and offer general support for the government's political agenda. Public diplomacy also enables Taiwan to challenge the more dominant narratives communicated by the PRC's own expanding programmes of public and cultural diplomacy. While it is certainly not a panacea for the problems Taiwan 
faces in international politics - public diplomacy will not, for example, persuade other governments to switch diplomatic recognition, nor will it result in Taiwan's readmission to the United Nations-public and cultural diplomacy can shape the way Taiwan interacts with its environment and manage its response to the challenges it faces. By devoting more attention and resources to its international communications and engagement activities, Taiwan will be in a stronger position to preserve its national security and interests, create diplomatic opportunities with other nation-states and organisations, and address the non-traditional threats that today require a more collaborative style of management.

Since the mid-199os Taiwan's external communicative activities have turned towards public and especially cultural diplomacy to raise Taiwan's international profile, explain Taiwan's position and predicament, and advocate policies that may benefit the strategic and political future of the island. The work of the Government Information Office (GIO) and, following the GIO's demise in 2012, the Ministry of Foreign Affairs reveal high-level political appreciation of the need to undertake international communications, engagement, and public diplomacy. However, successive governments have failed to embrace the potential of Taiwan's soft power and have therefore neglected to develop the kind of coherent public diplomacy programmes that may advance Taiwan's interests. Partly, this inadequacy is the result of poor strategic coordination at the top of government and within embassies and representative offices, as well as an overly hierarchical structure that prevents flexibility and slows down the communication process.

At the same time, often the best form of engagement occurs away from governments and state agencies. Cultural diplomacy centres on the contribution of non-state actors in facilitating dialogue, growing familiarity, and encouraging mutual understanding and respect through artistic and cultural programmes. In her essay for this volume Carla Figueira examines specifically the role of Taiwan's indigenous communities as cultural ambassadors.

A new strategic direction might orient Taiwan's public diplomacy around achievable goals, rather than desirable or unachievable objectives, such as trying to persuade other governments to switch their diplomatic recognition from the PRC to Taiwan, or rejoin the United Nations. Such ambitions are difficult for Taiwan to realise, especially in the short and medium term, though they may be supported by a long-term public diplomacy campaign that builds a momentum of international familiarity, empathy, and support. Thus it is possible to argue that such long-term goals may be realised by the collective support accumulated from other, small-scale campaigns directed towards other foreign policy objectives. Hence, identifying achievable short and mediumterm goals may include opening a dialogue about Taiwan's membership of 
more functional organisations such as the WHA and raising familiarity about Taiwan among international public opinion. This might require a coordinated programme of activities around a specific theme or set of themes, including why the international community should pay attention to Taiwan. The WHA provides a pivot for a narrative around the theme: why Taiwan matters and why the international community should care about the island. The story of Taiwan's democratisation and the progressing consolidation of democratic processes and procedures is a valuable soft power asset and may form a grand narrative that forms the context for other public diplomacy programmes. In addition to asking, 'What do we wish to achieve?', Taiwan's public diplomacy architecture should also ask: 'What does Taiwan stand for?' The commitment to global health and working with the international community to progress health initiatives is certainly worth promoting in the strongest possible terms. Thus, Taiwan's public diplomacy around the WHA should begin a discussion about its exclusion from the organisation despite Taiwan's substantial contribution to global health science and medical care and why this is acceptable to the international community. After all, Taiwan is the first country in Asia to implement universal health coverage, creating a system similar to the UK's National Health Service, and is committed to making sure that all foreign workers in Taiwan receive high standards of healthcare. Taiwan's healthcare professionals volunteer regularly in neighbouring countries; and of course diseases and health problems are not bound by national borders and do not care about politics. The SARS (severe acute respiratory syndrome) crisis demonstrated the value of collaborative approaches to medical care and Taiwan developed the means to share in real time medical samples for research and treatment. Taiwan's contribution to medical research and services is discussed here by Yen-Fu Chen. His contribution helps us to appreciate the enormous progress in Taiwan's medical services and healthcare provision, leading us to understand the role Taiwan has played — and continues to play_in providing healthcare to the region and the world, and in leading research in the medical scientists. Chen's essay helps us to answer the question, 'Why is membership of the WHA important for Taiwan and the world?' This connects with the provocative contribution to this issue by Colin Alexander who situates the issue of Taiwan's public diplomacy around membership of the WHA within a consideration of motivation. He interrogates the value of Taiwan's membership of such international organisations, the starting point for any strategy for inclusion, and questions the utility of moral arguments for membership. He concludes that moral arguments rarely work in diplomacy, which means Taiwan must re-examine its public diplomacy messaging. 
The essays in this topical section build upon these issues to understand how Taiwan may build its capacity in public and cultural diplomacy to seek membership of the WHA. The contributors-drawn from the social sciences, medical research, China studies, and the fields of communications and public diplomacy - contextualise the reasons why Taiwan's involvement in the WHA is necessary, the history of Taiwan's participation in global health initiatives, the reasons for exclusion from the WHA, and how Taiwan might generate support for membership among global audiences through a variety of media and cultural platforms. The essays recognise the limitations: there is an array of structural constraints on Taiwan's international relations, and 'better' public diplomacy will neither diminish nor demolish their influence. Rather, a carefully crafted communications strategy guided by appropriate structures and feedback mechanisms may help Taiwan manage and perhaps work around such obstacles.

\section{Acknowledgements}

I wish to thank all the participants in the 2018 workshop whose ideas inspired this topical issue. Special thanks to Representative David Y. L. Lin from the Taipei Representative Office in the UK; Chen Ya-hui also of the Representative Office; and Wang Liang-yu, Deputy General Director of the Department of International Organisations in Taiwan's Ministry of Foreign Affairs. I acknowledge the generous financial support of the Ministry of Foreign Affairs, ROc; and the Department of International Politics, Aberystwyth University, for hosting the event.

\section{Gary Rawnsley}

is Dean of the Faculty of Humanities and Social Sciences and Professor of Public Diplomacy at the School of International Studies, University of Nottingham Ningbo China (UNNC). He taught for 12 years in the School of Politics at the University of Nottingham (1994-2007). Following a two-year secondment to UNNC (2005-2007), he then became Professor of International Communication and Head of the Institute of Communications Studies at the University of Leeds (2007-2013), before joining Aberystwyth University in 2013 as Professor of Public Diplomacy in the Department of International Politics. He returned to the UNNC in 2018. Professor Rawnsley has numerous publications, including Political Communications and Democracy. He is a Fellow of the Royal Society of Arts. Gary Rawnsley is also Adjunct Professor at Asia University, Taichung (Taiwan) and at the Guangdong University of Foreign Studies (China). 